advocated his well-known views on the need to find a middle way between too restrictive prescribing leading to a flourishing black market and associated crime, and too free supply and availability leading to "epidemic intoxication".

Mr Allan Parry, Director of the Mersey Regional Drug Training Services, discussed the experience of the Liverpool needle and syringe exchange scheme. This was one of the first schemes in the UK to provide clean syringes and needles to injecting drug users on an exchange basis for dirty ones. They see on average 100 drug users each week, many of whom, although they may have been injecting drugs for many years, have never previously attended drug services. Finally, Dr John Strang of the Maudsley Drug Clinic gave a wide-ranging review of the issues around prescribing. He underlined the different types of prescribing and suggested those which might reasonably be undertaken by general practitioners and those which tended to be left to more specialist services.

For the afternoon session, participants divided into a number of discussion groups to look at the following specific issues:

(1) prescribing in rural and urban settings

(2) non-opiate prescribing

(3) opiate prescribing

(4) reducing versus maintenance policies

(5) prescribing for drug using parents.

What were the main themes that emerged from these groups? Firstly, that GPs should be more involved in prescribing, particularly in rural areas far from specialist centres. It was recognised that GPs' attitudes vary and that more training needs to be given, particularly at the vocational level but also at the undergraduate stage. Any GP prescribing to a drug user needs the close support of a community drug team or trained drug worker, particularly for help in counselling. The need for specialist help and guidance, both for GPs and for community drug teams, was emphasised. Though this can be provided by a Regional Drug Team or Drug Dependence Clinic, it was often felt that there should be a local psychiatrist with some experience in managing drug users. Those psychiatrists contemplating setting up a prescribing service were concerned as to whether they could meet the demands that might be put upon such a service. Interestingly, there was no great difference of views over the issue of long term 'maintenance' prescribing. It was seen as one option in certain circumstances where others had not worked.

The potential conflict of social workers on community drug teams was discussed. It was pointed out that if, as a member of such a team, a social worker became concerned at the circumstances of a child of addict parents, his responsibility would be to the welfare of the child. This might mean that the 'confidentiality' of the referral to the team would be compromised if a social services department then became involved. Finally, there was general agreement that some form of Regional guidelines would be helpful, particularly for general practitioners. These should indicate the available services in the Region and give some outline of good practice as far as prescribing is concerned.

Comment Conferences such as this are useful in helping to formulate Regional policies on matters such as prescribing for drug misusers. They tend, inter alia, to indicate where there are gaps in service provision and where there are deficiencies in existing services. The constructive manner in which participants discussed the various issues was noticeable. My impression is that having participants from a variety of disciplines, all interested in providing adequate services for drug misusers, helped to keep a broad focus to the discussion. I would commend this type of meeting to colleagues who may be formulating clinical policies for multi-disciplinary services.

\begin{abstract}
Award
The biennial award in memory of Professor Trevor Gibbens is to be made in October 1988. The Committee responsible for granting the award welcome applications from anyone working with offenders or victims. The award, in the region of $£ 500$, is given to the individual or organisation regarded as best able to use it, and applicants are required to state simply the purpose for which the money is needed.

Applications may be made for equipment, travel etc. and should be sent to Dr Graham Robertson, Secretary, Trevor
\end{abstract}

Gibbens Award, Institute of Psychiatry, De Crespigny Park, London SE5 8AF (to be received by the end of August 1988).

\section{Consultant Appointment}

The South Western Regional Health Authority have informed us that Dr P. M. White has been appointed Consultant in Child and Adolescent Psychiatry in North Devon and commenced his duties there on 14 March 1988. We were previously informed that $\operatorname{Dr} A$. K. Darwish would take up this post (Bulletin, January 1988, 12, 18). 